$\xi=-$ 国

\title{
The Relationship Between Oil and Natural Gas Prices on the Malaysian Economic Sectors
}

\author{
Nur Surayya Mohd Saudi', Wong Hock Tsen², Abdul Latif Harun'1, Zailin Zainal Ariffin', Nur Zahidah Syafii, Ah- \\ mad Shakir Mohd Saudi ${ }^{3,4,5 *}$, Mohd Khairul Amri Kamarudin', Muhammad Hafiz Md Saad ${ }^{6}$ \\ ${ }^{1}$ National Defense University of Malaysia, Sg. Besi Kuala Lumpur, Malaysia \\ ${ }^{2}$ Universiti Malaysia Sabah, Faculty of Business, Economics and Accountancy, Kota Kinabalu Sabah \\ ${ }^{3}$ Universiti Kuala Lumpur, Malaysian Institute of Industrial Technology, Persiaran Sinaran Ilmu \\ ${ }^{4}$ Institute of Medical Science Technology, Universiti Kuala Lumpur \\ ${ }^{5}$ Cybersecurity and System Research Unit, Faculty Science and Technology, Nilai, Malaysia \\ ${ }^{6}$ Faculty of Applied Social Sciences, Universiti Sultan Zainal Abidin, Gong Badak Campus, 21300 Kuala Nerus, Terengganu, Malaysia \\ *Corresponding authorE-mail: ahmadshakir@unikl.edu.my
}

\begin{abstract}
This study has investigated the relationship between the changes in oil and natural gas prices on the Malaysian economic sectors. Four economic sectors were selected namely manufacturing, services, agriculture, and mining. However, there was less study conducted at the sector level. Hence, the goal of this paper is to explore the impact of oil and gas prices on economic sectors GDP. This study has conducted econometrics modelling based on the ARDL bound testing with the spanning time series data from year 1987 to 2017 . The empirical findings revealed that the relationship between the oil and natural gas prices in the manufacturing and services sector is negative, while the agriculture sector showed a positive relationship, and the mining sector showed no relationship. The empirical findings concluded that the manufacturing and services sectors that consumed more energy are dependent on the price changes. Meanwhile, the agriculture sector is a highly subsidised sector which has a positive relationship with energy prices. In the policy recommendation, Malaysia has to apply the energy pricing policy by offering energy subsidy to the high energy consumed sectors. Finally, Malaysia should develop policies that can diversify its energy resources and increase the shares of renewable energy sources.
\end{abstract}

Keywords: oil price; natural gas price; GDP; economic sector.

\section{Introduction}

Oil and energies are the agents for the input of the production in a business that plays an important role in the supply chain that brings the final good to the consumer. The decisions of the households and businesses regarding energy use are influenced by the short-run changes in the economic activity as well as the longerterm trends. The increased volatility in the energy markets and crude oil has raised the investigation and discussion on this issue among the policymaker because it gives a significant impact on the different sectors. Hence, this paper intended to study the impact of Brent crude and natural gas prices on the economic sector. Malaysia has five economic sectors that contributed to GDP namely manufacturing, agriculture, services, mining, and construction sectors. Among the five sectors, the services sector outperformed the other sectors and contributed to Malaysia's GDP by $53.5 \%$. The manufacturing sector contributed $23 \%$, the agricultural sector contributed $8.8 \%$, and the construction sector contributed $4.4 \%$ [1]. It was reported that the domestic consumption of natural gas is the third highest energy share in the industrial sector [2]. Malaysia is equipped with high natural gas reserve that could last for at least 30 years [3]. This paper intended to investigate the impact of natural gas prices on the Malaysian economic sectors. Furthermore, the elasticity of substitution for the energy with the input of production is almost zero. The fluctuation and the increase in oil prices have pressured all industries, especially high energy consumption sectors such as manufacturing and services. The increase in energy cost has substantially reduced the competitive advantage in the high energy intensive economic sector. In addition, the energy represents the most important and costly industrial input in the developed and emerging countries [4].

\section{Literature Review}

There is a considerable amount of literature on energy economy, but there was less study on the impact of energy prices on the aggregate income. An early study by [5] concluded that the oil price hike affects the consumption in the economy. Furthermore, in [6] reported that the relationship between oil price and GDP performance are highly significant from year 1948 to 1994.

In $[5,7]$ argued that the macroeconomic policy that was implemented in the country has helped the country in its struggle with the oil price shock. In Malaysia, the consumption of natural gas in the industry began in the late 1980s. According to [8], the empirical results suggested that there is a long-run cointegration between the natural gas consumption on the economic growth. Moreover, they also concluded that natural gas consumption is important for the energy demand in Malaysia. In [9] studied the influence of fuel prices on the economic sectors in Malaysia, and they suggested that a continuous study on the impact of oil in specific economic sectors should be conducted because the impact of fuel in particular sectors is still unclear. In addition, in [10] study confirmed that 
Malaysia sectorial outputs have a short and long-run relationship with the oil price shock. The households were the most affected by the decrease of oil subsidies, and the situation deteriorates after the implementation of GST in April 2015. In [11] proposed that an extensive study on the impact of oil consumption on the economic sector is necessary to determine how the United States manage their oil consumption. In a different perspective, in [12] conducted a study on the impact of oil price on the manufacturing sector in Saudi Arabia because the manufacturing sector is the most important sector that can help the diversification process in Saudi Arabia's economy.

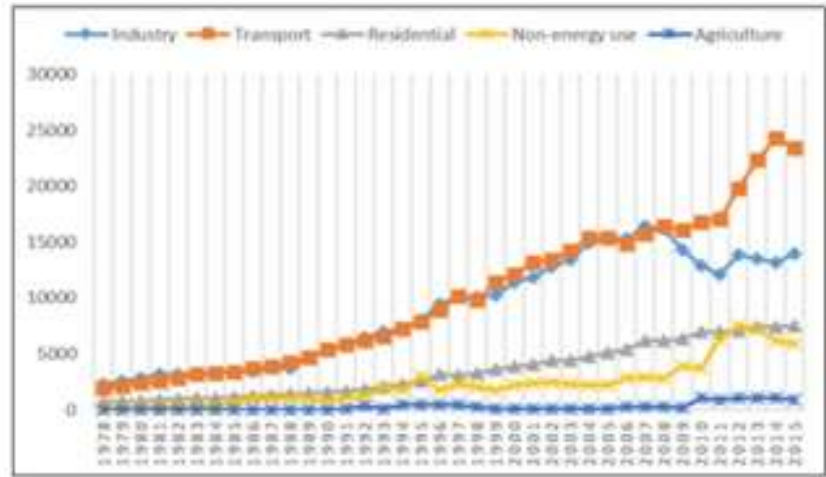

Fig. 1: World Brent crude, natural gas and LNG prices (FRED, 2018)

Note: Global price for natural gas in EU with US dollars per million metric British thermal units, global price for LNG in Asia with US dollars per million metric British thermal units, crude oil prices: Brent - Europe, dollars per Barrel.

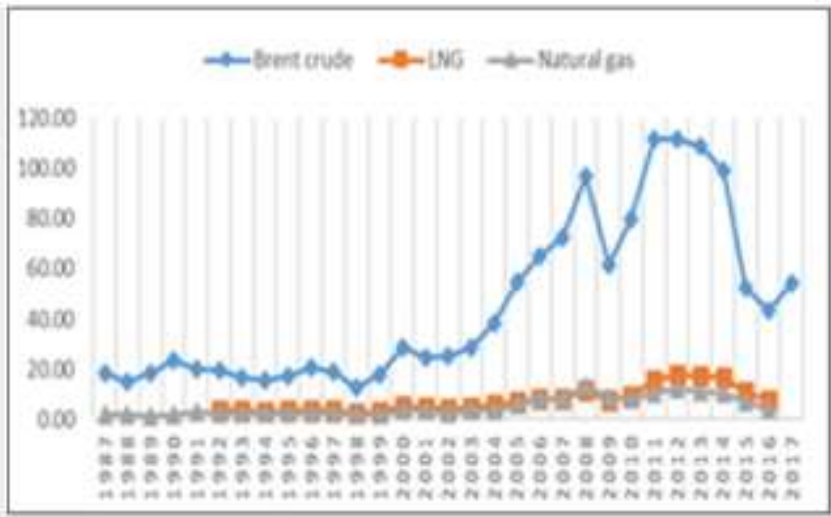

Fig. 2: Malaysia's petroleum consumption by sector (MER, 2017)

Note: Consumption per kilogram tonne of oil equivalent (ktoe).

This research objective intended to determine which economic sectors are impacted by the fluctuation of oil and natural gas prices and whether they have positive (direct) or negative (inverse) relationship. The author wanted to explore how the economic sector reacts to the oil price changes in order to suggest the oil prices or energy policies.

This paper intended to determine whether the fluctuations of the energy prices will affect any sectors in Malaysia. Some of the previous literature detected that the increase in oil price as the input of production would increase the income for the country, while some literature concluded that increase in oil price as input of production deteriorate the potential output. However, the effects on specific economic sector remained ambiguous as the heterogeneity effects may exist across the economic sectors. This paper looked into the potential of natural gas and revisited the impact of oil price on Malaysia's economy from a deeper segment based on selected economic sectors. Hence, this study intended to provide suggestions on the policy recommendation.

\section{Methodology}

This study has adopted the ARDL bound approach that was introduced by [13] and it was selected as the methodology due to its advantages where i) The problem of endogenous is not considered in this approach, and all variables are considered as endogenous. ii) ARDL model can be used in the case which is based on a combination of static I (0) and non-static variables with different accumulation rates. iii) ARDL is appropriate for descriptive statistics and correlation matrix in analyzing small sample size data and estimating the long-run and short-run relationship.

\subsection{Data}

This paper has employed a yearly time series data over the period from year 1987 to 2017 . The indicators for economic sectors data are based on the real GDP contribution in USD at the 2010 constant price. The economic data are obtained from the Department of Statistic Malaysia (DOSM), Energy information administration (EIA) and Federal Reserve Economic Data (FRED). This study has added the real exchange rate (RER) and consumer price index (CPI) as the economic agents. All the energies are in real value and converted to log before running the data analysis by EVIEWS

\subsection{Model specifications}

Following [12], we have constructs a multivariate model based on the underlying production function theory This study framed the objective of the study by exploring the impact of energy price on sectorial output production function relates quantities of physical output of the production process of physical input of production. Production function is a key concept of neoclassical theories that define marginal product and allocation of resource efficiently. Purpose of production function is to address the efficiency factor input in production in producing output. On the supply side of the economy, in addition to elements of labor and capital, energy is also considered to be a substantial element of production. According to [20], the direct effect of a change in energy prices on production and the corresponding indirect effects on the use of labor and capital inputs may be demonstrated simply by the production function:

$\mathrm{Q}=\mathrm{F}(\mathrm{K}, \mathrm{L}, \mathrm{E})$

where $\mathrm{Q}$ is output, $\mathrm{K}$ is capital inputs, $\mathrm{L}$ is labor inputs and $\mathrm{E}$ is energy inputs. Net output is given by:

$\mathrm{Y}=\mathrm{Q}-\mathrm{PEE}_{\mathrm{E}}$

where PE is the relative price of energy and the price of output is the numeraire. Substituting in (1) into (2) and setting the marginal product of each factor input equal to its price, the effect of a change in the price of energy on net output is given by:

$\frac{\mathrm{d} \ln Y}{\mathrm{~d} \ln P_{E}}=\left[\frac{P_{X} K}{Y}\right] \frac{\mathrm{d} \ln K}{\mathrm{~d} \ln P_{E}}+\left[\frac{P_{L} L}{Y}\right] \frac{\mathrm{d} \ln L}{\mathrm{~d} \ln P_{E}}-\left[\frac{P_{E} E}{Y}\right]$

where Pk and PL are the relative prices of capital and labor, respectively. Thus, the effect of an energy price change is given by the cost shares of each factor of production and the substitution effect of the price of energy on the quantity of labor and capital used in production. We have enhanced the model by adding the macroeconomic agents that can influenced the GDP in response on the impact of energy price changes.

Lsectors $=\mathrm{F}(\mathrm{LRBC}, \mathrm{LCPI}, \mathrm{LRER})$

Lsectors $=\mathrm{F}($ LRGAS, LCPI, LRER) 
where Lsectors is the GDP contributions from four selected economic sectors of manufacturing, services, agriculture and mining. Brent crude price (LRBC), Consumer Price Index (LCPI) and Real exchange rate (LRER).

\subsection{ARDL Model}

Model specifications lead to ARDL approach to estimates the following unrestricted error correction model (UECM) by Ordinary Least Squares Method (OLS) are as follows:

$$
\begin{aligned}
& \square \text { LSEC } \square \square_{0} \square \square_{0} \square \text { LSEC }_{\mathrm{t}} \square 1 \square \square \square \mathrm{N}_{0} \mathrm{LEP}_{\mathrm{t}} \square 1 \square \square{ }_{1} \mathrm{LCPI}_{\mathrm{t}} \square 1
\end{aligned}
$$

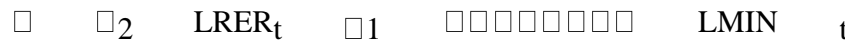

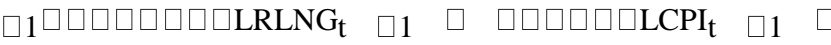

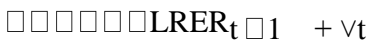

where LSEC represent the economic sector under investigation, while LEP represent on energy price. $\Delta$ is the first difference operator and $\mathrm{vt}$ is a white-noise disturbance term. Residuals for the UECM should be serially uncorrelated, and the model should be stable. The existence of cointegration relationship between variables in (1) is examined by testing the significance of the lagged levels of variables using the computed F-statistic.

Following [13], the F-statistic used for this test has a non-standard asymptotic distribution and generated two sets of critical values bounds (the lower critical value and the upper critical value). The lower critical value corresponding to the case where all variables are I (0) and upper critical value corresponding to the case where all variables are I (1). If the computed F-statistic exceeds the upper critical bound, then the null hypothesis of the no cointegration is rejected and we can conclude that there is evidence of a long-run relationship. If it falls below the lower critical value, we do not reject the null hypothesis of no cointegration. Finally, if the Fstatistic is between the lower and upper critical bounds, the result is not conclusive.

\subsection{Long Run Relationship Hypothesis}

H0: $\theta 0=\theta 1=\theta 2=\theta 3=0$ (no long-run relation-ship) H1: $\theta 0 \neq \theta 1 \neq \theta 2 \neq \theta 3 \neq 0$ (long-run relationship exists)

\section{Results and Discussion}

\subsection{Empirical Analysis}

\subsubsection{Unit root test}

Before proceeding with the ARDL bound test, this study tested the stationary status of all variables to determine their order of integration to ensure that the variables are not (2) stationary to avoid spurious results. The Augmented Dickey-Fuller (ADF) and Kwiatkowski-Phillips-Schmidt-Shin (KPSS) were used to test the order of integration of the variables. The unit root test showed that none of the variables is integrated at (2). Refer to Table 1 and we can proceed to ARDL methodology in our model. Note: ***, $* *$ and $*$ are $1 \%, 5 \%$ and $10 \%$ of significant levels respectively which applied in all tables.

\subsubsection{Bound Test}

In the first step of the ARDL analysis, this study has tested the presence of long-run relationships. Before testing the existence of the long-run relationship among the variables, it is important to decide the order of the lag of the ARDL. The results are shown in Table 2. The results of the computed F-statistics and the critical values suggested by [13] are well beyond the lower and upper critical value at $1 \%$ and $5 \%$ level of significance. This is the evidence of the strong long-run relationship among the variables.
Table 1: ARDL Bound test

\begin{tabular}{|c|c|c|}
\hline Model & AIC (Lag order) & F Statistic \\
\hline \multicolumn{3}{|l|}{ LMAC } \\
\hline Brent & $(1,1,1,0)$ & $6.26^{* * * *}$ \\
\hline Gas & $(1,1,1,0)$ & $5.54^{* * *}$ \\
\hline \multicolumn{3}{|l|}{ LAGRI } \\
\hline Brent & $(1,4,3,4)$ & $7.626^{\text {**** }}$ \\
\hline Gas & $(2,4,3,4)$ & $9.92^{* * * *}$ \\
\hline \multicolumn{3}{|l|}{ LSER } \\
\hline Brent & $(1,0,1,0)$ & $4.510^{* *}$ \\
\hline Gas & $(1,0,1,0)$ & $4.707^{* *}$ \\
\hline \multicolumn{3}{|l|}{ LMIIN } \\
\hline Brent & $(1,0,0,2)$ & $7.648^{* * *}$ \\
\hline Gas & $(1,0,0,2)$ & $7.809^{* * * *}$ \\
\hline $\begin{array}{c}\text { Critical Values } \\
\text { for } \\
\text { F-statistics } \#\end{array}$ & Lower Bound, I (0) & $\begin{array}{c}\text { Upper Bound, } \\
\text { I(1) }\end{array}$ \\
\hline $1 \%$ & 3.41 & 4.68 \\
\hline $5 \%$ & & 3.79 \\
\hline $10 \%$ & $\begin{array}{l}2.62 \\
2.26\end{array}$ & 3.35 \\
\hline
\end{tabular}

\subsubsection{ARDL estimation of long -run relationship}

The estimated coefficients of the long-run relationship showed that there is a negative relationship between Brent crude price with the manufacturing sector and services sector, and there is a positive long-run relationship between the Brent crude price with the agriculture sector. However, there is no long-run relationship between Brent crude and natural gas prices in the mining sector (refer Table 2).

Table 2: Long- run relationship

\begin{tabular}{cll}
\hline & IV & Coefficient \\
\hline LMAN & Brent & $-0.3343^{* *}$ \\
& Gas & $-0.5031^{* *}$ \\
\hline LSER & Brent & $-0.1272^{*}$ \\
& Gas & -0.1109 \\
\hline LMIN & Brent & 0.2148 \\
& Gas & 0.0651 \\
\hline LAGRI & Brent & $0.4001^{* * *}$ \\
& Gas & 0.0085 \\
\hline
\end{tabular}

\subsubsection{ARDL estimation on short-run dynamics}

The short-run dynamic of the model revealed the information speed of the adjustment process to restore the long-run equilibrium. Table 3 shows the model with Brent crude price on manufacturing, services, agriculture, and mining is negative with the significant implies of about $0.36 \%, 25 \%, 65 \%$, and $78 \%$, while the natural gas price on manufacturing, services, agriculture, and mining implies about $21 \%, 21 \%, 63 \%$, and $60 \%$ respectively of the disequilibrium for one year to adjust back to the long-run equilibrium. 
Table 3: Short-run magnitude

\begin{tabular}{|c|c|c|c|c|}
\hline & IV & Coefficlent & & \\
\hline \multirow[t]{2}{*}{ LMAN } & Brent & 0.0395 & $\mathrm{ECT}(-1)$ & $-0.0036^{* \cdots *}$ \\
\hline & Gas & 0.0000 & $\operatorname{ECT}(-1)$ & $-0.2080^{=\cdots}$ \\
\hline \multirow[t]{2}{*}{ LSER } & Brent & -0.315 & $\mathrm{ECT}(-1)$ & $-0.2477^{* x:=}$ \\
\hline & Gas & -0.0226 & $\mathrm{ECT}(-1)$ & $-0.20409^{x=}$ \\
\hline \multirow[t]{2}{*}{ LMIN } & Brent & 0.0483 & $\mathrm{ECT}(-1)$ & $-0.671^{*=2}$ \\
\hline & Gas & 0.0408 & $\operatorname{ECT}(-1)$ & $-0.6274^{k * *}$ \\
\hline \multirow[t]{2}{*}{ LAGRI } & Brent & $-0.2513^{* *}$ & $\operatorname{ECT}(-1)$ & $-0.7805^{2 \ldots .}$ \\
\hline & Gas & $-0.1328^{k *}$ & $\mathrm{ECT}(-1)$ & $-0.6081^{k * *}$ \\
\hline
\end{tabular}

\subsection{Diagnostics and stability test}

The last issue is related to the goodness of fit of the ARDL models This study has performed a series of diagnostic and stability tests. The diagnostic tests have examined the serial correlation using the following: 1) Breusch-Godfrey Serial Correlation; and 2) Heteroskedasticity test: Breusch-Pagan-Godfrey and normality test. The diagnostic tests revealed no evidence of misspecification and autocorrelation. This study has utilised the cumulative sum of recursive residuals (CUSUM) and the cumulative sum of squares of recursive residuals (CUSUMSQ) to test the structural stability. The results of CUSUM and CUSUMSQ stability test indicated that the estimated coefficients of all models are stable (refer Table 4).

Table 4: Diagnostics Test

\begin{tabular}{lccc}
\hline & $\begin{array}{c}\text { A. Serial } \\
\text { correlation } \\
\text { X 2 (1) } \\
\text { [p-value] }\end{array}$ & $\begin{array}{c}\text { B. Normality C. Heteroscedasticity } \\
\text { X 2 (2) } \\
\text { [p-value] }\end{array}$ & $\begin{array}{c}\text { X 2 (1) } \\
\text { [p-value] }\end{array}$ \\
\hline LMAC & & & \\
LRBC & 0.4899 & 0.3665 & 1.3388 \\
& {$[0.5909]$} & {$[0.8325]$} & {$[0.6722]$} \\
\hline LRGAS & 0.7783 & 0.04825 & 3.2204 \\
& {$[0.3553]$} & {$[0.9761]$} & {$[0.2334]$} \\
LAGRI & & & \\
LRBC & 0.0504 & 0.01178 & 4.9689 \\
& {$[0.7128]$} & {$[0.9941]$} & {$[0.9983]$} \\
LRGAS & 0.60403 & 0.07258 & 1.7154 \\
& {$[0.1700]$} & {$[0.9643]$} & {$[1.000]$} \\
\hline LSER & \multicolumn{3}{c}{} \\
LRBC & 1.0747 & 0.6083 & 1.3994 \\
& {$[0.2572]$} & {$[0.7377]$} & {$[0.4019]$} \\
LRGAS & 1.1646 & 0.8548 & 1.4503 \\
& {$[0.2254]$} & {$[0.6489]$} & {$[0.3830]$} \\
\hline LMIN & \multicolumn{3}{c}{} \\
LRBC & 0.0559 & 2.7093 & 0.3516 \\
& {$[0.9225]$} & {$[0.2580]$} & {$[0.9082]$} \\
LRGAS & 0.5632 & 2.1118 & 0.5351 \\
& {$[0.4996]$} & {$[0.3478]$} & {$[0.8059]$} \\
\hline
\end{tabular}

Fig. 3 presented the CUSUM and CUSUMQ in order to proof the reliability of the data. All the explained model is stable at $5 \%$ significant level. The plots of variable are inside the critical bound.

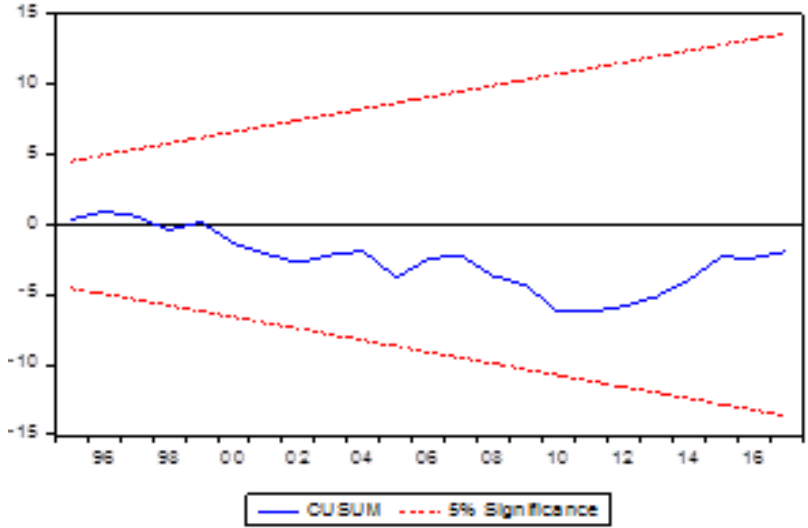

(a)

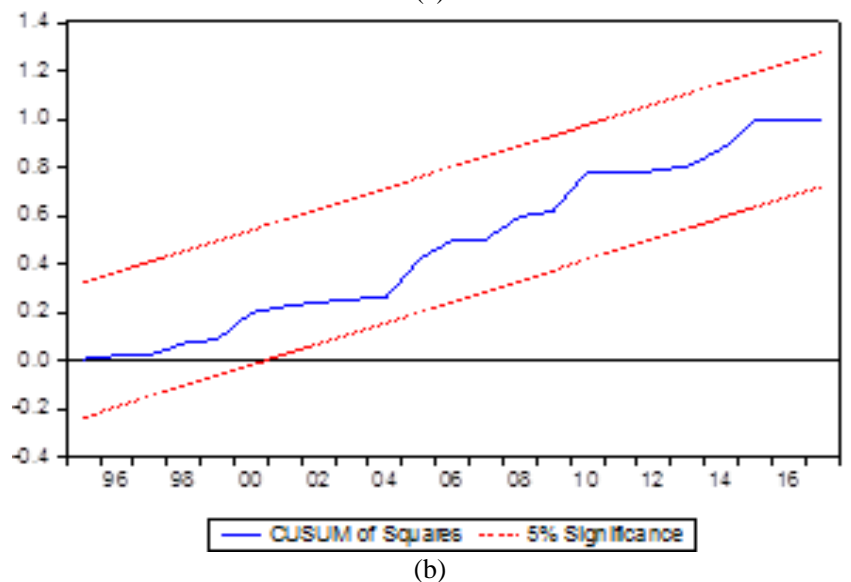

Fig. 3: Stability Test (a) CUSUM Test (b) CUSUMQ Test

\section{Conclusion}

This paper has contributed to the field of energy economics in two important ways. First, this study has utilised the measures of disaggregate Gross Domestic Products in four sectors and provided a comprehensive analysis. Second, this study has employed a relatively new time series approach that is capable of uncovering the relationships that might be overlooked when using conventional methods. The negative long-run relationship between Brent crude price on the manufacturing and services sectors indicated that the long-run increase of the Brent crude price could dampen the output for these sectors that represent the highest contributors for Malaysia's overall GDP. The results are in line with [14-17].

The negative long-run relationship support the classical supply theory that suggest hike in production input reduce the overall potential output. A decline in oil prices is beneficial to oil exporters due to the quantity effect that outweighs the price effect. The positive long-run relationship between the agriculture sector and Brent crude oil price is due to the agriculture sector, which is highly subsidised by the Malaysian government to maintain the sustainability of the agriculture sector. The implementation of National Agriculture Policy (NAP1) intended to help the agriculture sector especially the small farmer to increase the value of the agriculture products for the export market. Furthermore, NAP2 was developed from year 1992 to 2010 by providing incentives through the development of the infrastructure of the agriculture sector and the increment of production, competitiveness, and sustainable production. The increase in the input of production (Brent crude and natural gas) does not give a negative implication on the agriculture sector.

However, previous literature $[18,19]$ confirmed there was a negative relationship for the crude oil price on the agriculture sector as this energy is the direct input of the production. Finally, the longrun relationship revealed that the mining sector has no relationship with the Brent crude and natural gas prices because it is believed that the production and exploration of the oil and natural gas will continue and remain vital for the energy demand. Overall, the 
empirical findings concluded that the sectors which consumed the most energy are dependent on the price changes. In the policy recommendation, Malaysia has to apply the energy pricing policy and offer energy subsidy to the sectors with high energy consumption. Finally, Malaysia should develop policies that can diversify its energy resources and increase the shares of renewable energy sources.

\section{Acknowledgement}

The authors wish to express gratitude to Associate Professor Wong Hock Tsen for a constructive comments and National Defense University of Malaysia for funding support.

\section{References}

[1] https://www.dosm.gov.my/v1/.

[2] Suruhanjaya Tenaga. (2016). http://www.st.gov.my/index.php/en/.

[3] Business Monitor International Ltd. (2016). Q1 2016: Malaysia oil and gas report-includes 10-year forecasts to 2024 https://community.ump.edu.my/ecommstaff/sites/default/library/su bfolders/12780/1/BMI_Malaysia_Oil_26_Gas_Report_Q12016.pd f.

[4] Eksi, I. H., Izgi, B. B., \& Senturk, M. (2011). Reconsidering the relationship between oil prices and industrial production: Testing for cointegration in some of the OECD countries. Eurasian Journal of Business and Economics, 4(8), 1-12.

[5] Hamilton, J. D. (1996). This is what happened to the oil pricemacroeconomy relationship. Journal of Monetary Economic, 38(2), 215-220.

[6] Hooker, M. A. (1996). What happened to the oil pricemacroeconomy relationship? Journal of Monetary Economics, 38(2), 195-213

[7] Kilian, Lutz, Vigfusson, Robert J., 2011. Nonlinearities in the oil price-output relationship. Macroeconomic Dynamics 15, 337-363.

[8] Hussain, A. B., \& Azlina, A. (2010). Energy use in agriculture sector: Input-output analysis. Proceedings of the 2nd Terengganu International Business and Economics Conference, pp. 111-121.

[9] Eksi, I. H., Izgi, B. B., \& Senturk, M. (2011). Reconsidering the relationship between oil prices and industrial production: Testing for cointegration in some of the OECD countries. Eurasian Journal of Business and Economics, 4(8), 1-12.

[10] Ee, C. Y. (2015). The effect of oil price in Malaysia economy sectors. Labuan Bulletin of International Business and Finance, 13 $1-9$.

[11] Brown, S. P. A. (2017). Natural gas vs. oil in U.S. transportation: Will prices confer an advantage to natural gas? Energy Policy, 110, 210-221.

[12] Mahboub, A. A., \& Ahmad, H. E. (2016). The effect of oil price shocks on the saudi manufacturing sector. Economics, 5(3), 230238

[13] Pesaran, M. H., Shin, Y., \& Smith, R. J. (2001). Bounds testing approaches to the analysis of level relationships. Journal of Applied Econometric, 16, 289-326.

[14] Ee, C. Y. (2015). The effect of oil price in Malaysia economy sectors. Labuan Bulletin of International Business and Finance, 13, $1-9$.

[15] Ebaidalla, E. M. (2014). The effects of oil price volatility on the sudanese economy. Eastern Africa Social Science Research Review, 30(1), 1-26.

[16] Fukunaga, I., Hirakata, N., \& Sudo, N. (2010). The effects of oil price changes on the industry-level production. National Bureau of Economic Research

[17] Shaari, M. S., Hussain, E., \& Abdullah, H. (2012). The effects of oil price shocks and exchange rate volatility on inflation: Evidence from Malaysia. International Business Research, 5(9), 106-112.

[18] Odeniyi, K. A. (2013). Effect of crude oil price on agricultura productivity in Nigeria (1981-2010). International Journal of Applied Agriculture and Apiculture Research, 9, 131-139.

[19] Ikram, H., \& Waqas, M. (2014). Crude oil price and agriculture productivity growth in Pakistan. World Applied Sciences Journal, 32(4), 642-649.

[20] Bohi, R. B. (1991). On the macroeconomic effects of energy price shocks. Resources and Energy, 13, 145-162. 